Journal of Advanced Research in Fluid Mechanics and Thermal Sciences

Journal homepage: www.akademiabaru.com/arfmts.html ISSN: $2289-7879$

\title{
Experimental Investigation of the Effectiveness of Jet Impingement Cooling System on the Pressure Side of the Turbine Blade
}

\author{
Nur Farah Hanis Kamalulzaman ${ }^{1}$, Nurul Farhanah Azman ${ }^{1}$, Mohamad Nor Musa $^{1,}{ }^{*}$, Syahrullail \\ Samion $^{1}$
}

1 School of Mechanical Engineering, Faculty of Engineering, Universiti Teknologi Malaysia, 81310 Skudai, Johor, Malaysia

\begin{tabular}{|c|c|}
\hline ARTICLE INFO & ABSTRACT \\
\hline $\begin{array}{l}\text { Keywords: } \\
\text { Jet impingement; pressure side; height } \\
\text { to diameter ratio }\end{array}$ & $\begin{array}{l}\text { The effectiveness of the jet impingement system on the turbine blade pressure side } \\
\text { has been experimentally investigated. The effects of height-to-diameter ratio and air } \\
\text { velocity on the effectiveness of jet impingement were studied. Experiments was } \\
\text { performed under varying height-to-diameter ratios (H/D }=5,10,15,20) \text { where the } \\
\text { distance from the nozzle to the pressure side surface ranged from } 20,40,60 \text { and } 80 \\
\mathrm{~mm} \text { with a constant nozzle diameter of } 4 \mathrm{~mm} \text {. The Nusselt number is calculated to } \\
\text { determine the cooling effect of the pressure side model surface. Experiments were } \\
\text { also performed at varying air velocity at } 6.4 \mathrm{~m} / \mathrm{s} \text { and } 12.6 \mathrm{~m} / \mathrm{s} \text {. The findings revealed } \\
\text { that there was no direct relationship between Nusselt number and } \mathrm{H} / \mathrm{D} \text { ratio where } \\
\text { the optimum cooling impact at a velocity of } 6.4 \mathrm{~m} / \mathrm{s} \text { was found to be at } H / D=15 \text {, } \\
\text { whereas at a velocity of } 12.6 \mathrm{~m} / \mathrm{s} \text { it was found to be at } H / D=5 \text {. The findings also } \\
\text { reveal that the amount of Nusselts rises as the air velocity increases. }\end{array}$ \\
\hline
\end{tabular}

\section{Introduction}

Gas turbine, also referred to as a combustion turbine, is commonly used for multiple applications, such as electricity generation, aircraft propulsion and other industrial applications [1]. The gas turbine runs at exceptionally high temperatures between $1600 \mathrm{~K}$ and $1900 \mathrm{~K}$ in order to improve the efficiency of the turbine [2]. However, higher operating temperature of the gas turbine can lead to wear, failure and fatigue of the turbine blade after a certain period of time [3]. This constraint renders cooling in gas turbine systems a critical field of heat transfer research. The cooling system plays a key role in maintaining the turbine components temperature below critical level and in avoiding overheating failure [4]. Several internal cooling methods may be used to improve the heat transfer of turbine blades, including rib turbulators, pin fins, dimples and jet impingement cooling [3,5]. Previously, the authors have studied the use of palm oil to reduce the friction rate in the system. Good lubrication will also help the cooling system [6-13].

\footnotetext{
* Corresponding author.

E-mail address: mnormusa@utm.my
}

https://doi.org/10.37934/arfmts.84.1.3342 
The jet impingement cooling system is extensively studied numerically and experimentally by several researchers due to its advantages, including its relatively simple, extremely high heat transfer rate, and can be used in numerous industrial applications [14-16]. A significant number of experiments have been performed on the factors affecting jet impingement cooling, including the shape of the nozzle, the angle of the nozzle, the velocity of the air, the height-to-diameter ratio and the number of Reynolds. Singh et al., [17] experimentally and numerically studied the influence of the shape of the nozzle, i.e. circular, square and rectangular, on the cooling of the circular cylinder jet impingement. Experiments and numerical investigations were performed in two sets of conditions (i) for fixed $\mathrm{Re}_{\text {hyd }}$ (i.e. same average velocity and same hydraulic diameter) and (ii) for fixed $\overline{R e}_{\text {hyd }}$ (i.e. same mass flow rate and same hydraulic diameter). They found that the rectangular nozzle shows the highest heat transfer rate between the nozzle shape for the fixed $\mathrm{Re}_{\text {hyd }}$, but the circular shape shows the highest heat transfer rate between the nozzle shape for the fixed $\overline{R e}_{h y d}$. Bakar [18] experimentally studied the influence of the angle of the nozzle, the gap between the nozzle and the impinge surface and the Reynolds number. They recorded that the Nusselt number at a higher angle $\left(90^{\circ}\right)$ was higher than that at a lower angle $\left(30^{\circ}, 45^{\circ}, 60^{\circ}\right)$. They also observed that the Nusselt number was higher with a greater Reynolds number and a narrower gap between the nozzles to the impinge surface.

Liu and Feng [19] performed numerical studies on the impingement cooling of the leading edge gas turbine edge. Numerical investigations are carried out at various locations of the jet nozzle (E/D: 0.70, 1.60, 2.52, 3.42 and 4.32) and the jet Mach number (M: 0.1, 0.3, 0.5 and 0.7). It was found that the area weighted average Nusselt number of the target surface increases with Mach number, and decreases with E/D. It also indicates that both the streamwise $\left(\mathrm{Nu}_{\mathrm{st}}\right)$ and the spanwise length of the weighted average Nusselt number $\left(\mathrm{Nu}_{\mathrm{sp}}\right)$ are observed to be higher at the lower $\mathrm{E} / \mathrm{D}$ and higher at the higher Mach number. Liu et al., [20] numerically and experimentally evaluate the effects of the location of the jet nozzle and the Reynolds number (Re) on the blade leading edge of the impingement heat transfer. The locations of the jet nozzle employed for the study were $E / D=0$, 0.5 and 1.0, whereas the amount of Re employed was $R e=12000,15000$ and 20000. The heat transfer enhancement was noticed to be correlated with E/D and Re. The highest $\mathrm{Nu}$ on the target surface was observed for $\operatorname{Re}<15000$ at $E / D=0.5$. However, in the case of $R e=20000$, the $\mathrm{Nu}$ decreases with the rise in E/D. Their results connected to the combined behaviour of vortices magnitude, jet velocity and turbulent kinetic energy close to the target surface.

As can be seen from the literature review, researchers have done major work on the impingement cooling for the gas turbine blade leading edge, but few studies on the impingement cooling on the pressure side have been published. The purpose of this analysis is therefore to determine the effectiveness of the jet impingement cooling on the pressure side of the RR Trent 970-B84 turbine blade surface on the basis of two criteria, which are the nozzle to surface distance and the velocity of air employing a circular shape nozzle.

\section{Methodology}

Present study focused on acquiring temperatures for the turbine blade pressure side model. The experimental setup presented in Figure 1 consists mainly of the nozzle, pressure regulator, compressor, pressure side model, thermocouples, thermocouple data logger and heater. The circular capillary channel, with a diameter of $4 \mathrm{~mm}$, acts as a nozzle and is located at an angle of $90^{\circ}$ at the top of the pressure side model. The position of the nozzle was placed at $90^{\circ}$ since the previous researcher observed that the heat transfer rate was the maximum at this angle compared to the lower angle [18]. The pressure side model was produced using a zinc plate and the dimension 
replicates the scaled down of the RR-Trent 970-84B turbine blade. Zinc material has been chosen because it is commonly used in industrial applications. The thermocouples were mounted at five separate locations, with a gap of $30 \mathrm{~mm}$ for each thermocouple, along the centre line of the model. The photograph of the pressure side model is shown in Figure 2. Thermocouple 4 was set as the temperature control as it is situated in the centre of the heat source at the highest temperature.

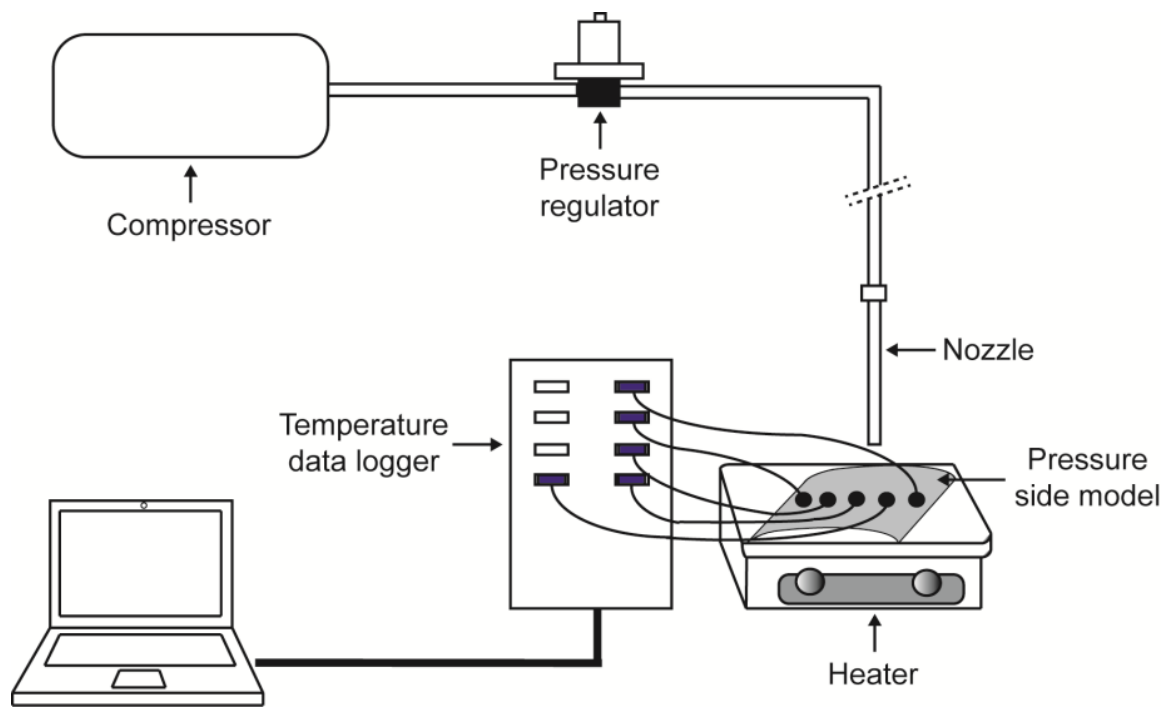

Fig. 1. Schematic diagram of experimental setup

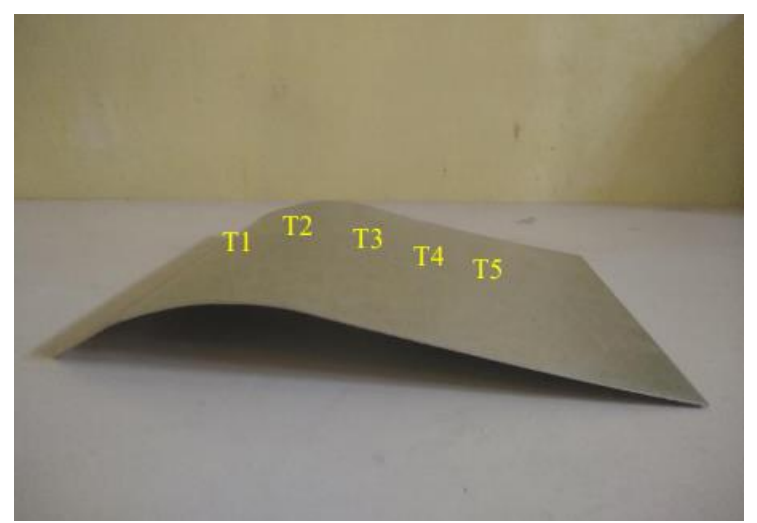

Fig. 2. Photograph of the pressure side model and the position of the thermocouple

The pressure side model was heated by the heater until the thermocouple 4 had achieved the target temperature $\left(\sim 55^{\circ} \mathrm{C}\right)$. The initial temperature of the pressure side model surface was determined in order to minimise the measurement errors related to its dimension. The compressed air supplied by the compressor is sent to the pressure regulator. The airflow of the compressed air was controlled by the pressure regulator. First, the compressed air flows into the capillary channel, and the cooling airflow impairs the pressure side model for 30 seconds. The temperature of the cooling phase was recorded. In the current study, two different parameters, i.e. the ratio of the nozzle distance from the pressure side surface to the jet nozzle diameter (H/D) and the velocity of air, were varied in order to test the efficacy of the jet impingement cooling on the pressure side model. Variations of parameters included in the present analysis can be found in Table 1 . The temperature measured was used to calculate the following dimensionless parameter (Nusselt number). 


$$
N u=\frac{h L_{c}}{k}
$$

where $h$ is the convective heat transfer coefficient $\left(\mathrm{W} / \mathrm{m}^{2} . K\right), \mathrm{L}_{c}$ is the characteristic length of the contact area $(\mathrm{m})$ and $\mathrm{k}$ is the thermal conductivity of the air $(\mathrm{W} / \mathrm{m} . \mathrm{K})$. The heat transfer coefficient is defined as

$h=\frac{\dot{m} \Delta T C_{p}}{A_{s}\left(T_{s}-T_{\infty}\right)}$

where $\dot{m}$ is the mass flow rate $(\mathrm{kg} / \mathrm{s}), \Delta \mathrm{T}$ is the temperature difference $(\mathrm{K}), \mathrm{C}_{\mathrm{p}}$ is the specific heat of air $(\mathrm{J} / \mathrm{kg} . \mathrm{K}), \mathrm{A}_{\mathrm{s}}$ is the surface area through which convection heat transfer takes place $\left(\mathrm{m}^{2}\right), \mathrm{T}_{\mathrm{s}}$ is the surface temperature $(K)$ and $T_{\infty}$ is the stream temperature $(K)$.

Table 1

Parameters varied in the current study

\begin{tabular}{lll}
\hline Parameter & Value & Unit \\
\hline Height to diameter ratio (H/D) & $5,10,15,20$ & - \\
Distance from nozzle to pressure side surface & $20,40,60,80$ & $\mathrm{~mm}$ \\
Velocity & $6.4,12.6$ & $\mathrm{~m} / \mathrm{s}$ \\
\hline
\end{tabular}

\section{Results}

\subsection{Effect of Height to Diameter Ratio (H/D)}

In order to explore the effect of the height-to-diameter ratio $(H / D)$ on the jet impingement cooling method of the pressure side model, the experiment is carried out at four separate $H / D$ ratios: $5,10,15$ and 20 , based on the gap between the nozzle and the pressure side surface of 20 $\mathrm{mm}, 40 \mathrm{~mm}, 60 \mathrm{~mm}$ and $80 \mathrm{~mm}$ at a constant nozzle diameter of $4 \mathrm{~mm}$. Figure 3 indicates the difference of the final temperature of each thermocouple location for a particular H/D at a velocity of (a) $12.6 \mathrm{~m} / \mathrm{s}$ and (b) $6.4 \mathrm{~m} / \mathrm{s}$. It is found that the cooling pattern over the surface of the pressure side model is identical for all H/D. The lowest final temperature values in Figure 3(a) vary from $22.78^{\circ} \mathrm{C}$ to $23.62^{\circ} \mathrm{C}$ at thermocouple $2(\mathrm{~T} 2)$. Whereas in Figure $3(\mathrm{~b})$, the lowest final temperature values vary from $22.61^{\circ} \mathrm{C}$ to $23.27^{\circ} \mathrm{C}$, which is also at $\mathrm{T} 2 . \mathrm{T} 2$ has the lowest final temperature since it is near to the middle position of the nozzle. It can be shown that, when the position of the thermocouple is farther from the middle position of the nozzle, the final temperature rises. Since T4 is closer to the centre location of the nozzle, its final temperature was higher than that of T5. This is because T4 was set as a control thermocouple and observed the maximum initial temperature relative to the other location of thermocouple, as seen in Table 2 . Under high velocity, see Figure 3(a), it can be shown that the final temperature rose as the H/D ratio increased. However, various patterns were observed at low velocity; see Figure 3 (b). It indicates that the final temperature decreased when the H/D ratio rose from 5 to 15 , but then decreased when H/D was 20. The lowest final temperature for both velocities is reported at $T 2$, which is found to be the stagnation point of the pressure side surface. 

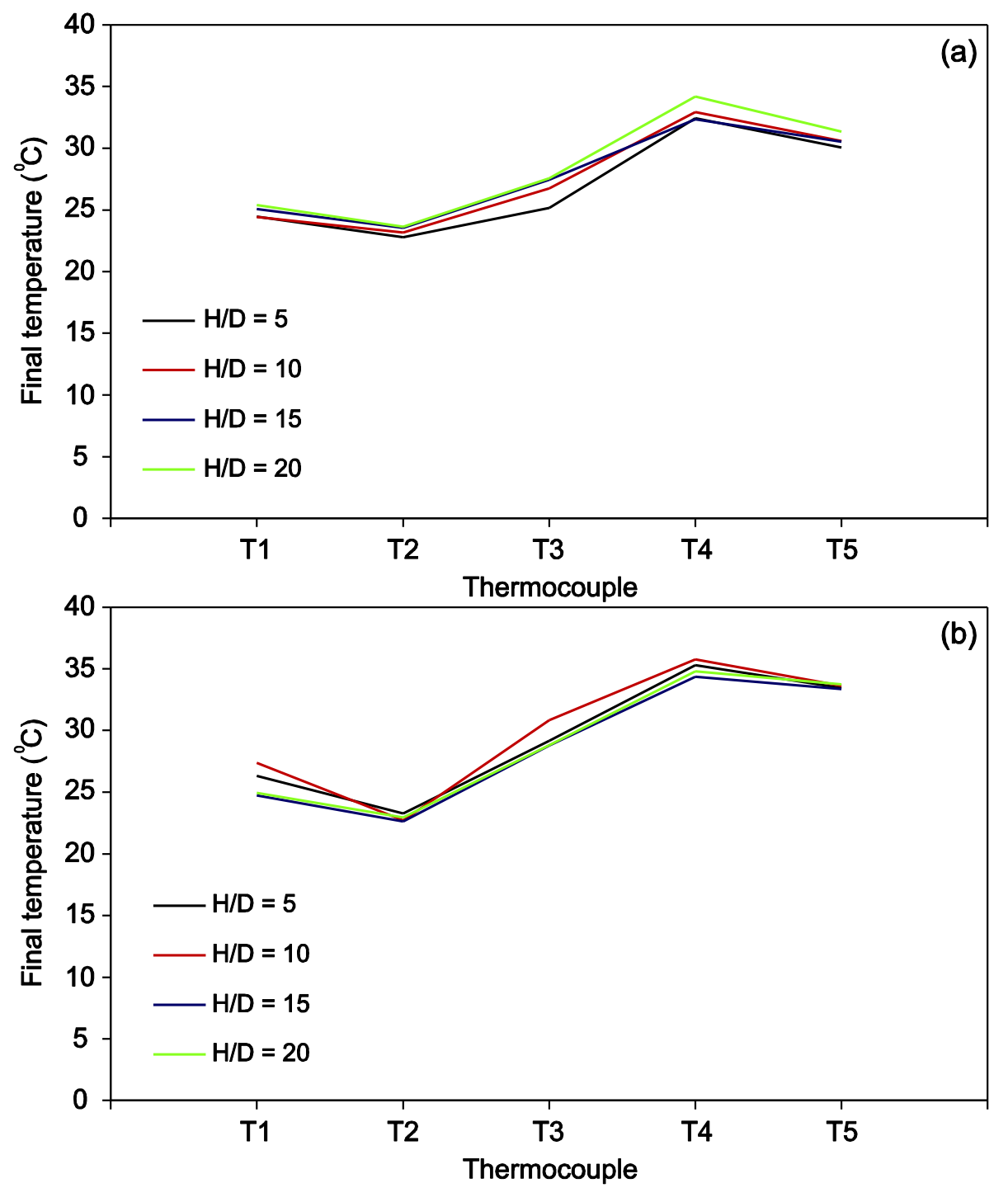

Fig. 3. Variation of final temperature of each thermocouple position with different $H / D$ at a velocity of (a) $12.6 \mathrm{~m} / \mathrm{s}$ and (b) $6.4 \mathrm{~m} / \mathrm{s}$

Table 2

Experimental results of initial and final temperature with different $H / D$ at a velocity of (a) $12.6 \mathrm{~m} / \mathrm{s}$ and (b) $6.4 \mathrm{~m} / \mathrm{s}$

\begin{tabular}{|c|c|c|c|c|c|c|c|c|c|c|c|}
\hline \multirow{3}{*}{$\begin{array}{l}\text { Velocity } \\
(\mathrm{m} / \mathrm{s})\end{array}$} & \multirow[t]{3}{*}{$H / D$} & \multicolumn{10}{|c|}{ Temperature $\left({ }^{\circ} \mathrm{C}\right)$} \\
\hline & & \multicolumn{2}{|l|}{ T1 } & \multicolumn{2}{|l|}{$\mathrm{T} 2$} & \multicolumn{2}{|l|}{ T3 } & \multicolumn{2}{|l|}{ T4 } & \multicolumn{2}{|l|}{ T5 } \\
\hline & & Initial & Final & Initial & Final & Initial & Final & Initial & Final & Initial & Final \\
\hline \multirow[t]{4}{*}{12.6} & 5 & 50.42 & 24.45 & 51.25 & 22.78 & 50.30 & 25.15 & 55.11 & 32.43 & 52.08 & 30.05 \\
\hline & 10 & 50.13 & 24.44 & 51.6 & 23.18 & 50.60 & 26.75 & 55.25 & 32.92 & 52.21 & 30.60 \\
\hline & 15 & 51.15 & 25.06 & 52.4 & 23.54 & 51.20 & 27.44 & 55.11 & 32.33 & 53.02 & 30.52 \\
\hline & 20 & 51.09 & 25.39 & 52.12 & 23.62 & 50.41 & 27.56 & 55.19 & 34.2 & 52.45 & 31.34 \\
\hline \multirow[t]{4}{*}{6.4} & 5 & 50.73 & 26.32 & 51.44 & 23.27 & 50.11 & 29.15 & 55.24 & 35.29 & 52.39 & 33.45 \\
\hline & 10 & 51.07 & 27.37 & 51.81 & 22.72 & 50.60 & 30.82 & 55.14 & 35.74 & 52.01 & 33.61 \\
\hline & 15 & 49.56 & 24.72 & 50.81 & 22.61 & 49.22 & 28.77 & 55.13 & 34.35 & 52.80 & 33.35 \\
\hline & 20 & 48.35 & 24.94 & 49.47 & 22.94 & 48.49 & 28.81 & 55.12 & 34.77 & 54.29 & 33.73 \\
\hline
\end{tabular}

Figure 4 shows the variance of the Nusselt number of each thermocouple location with different H/D at a velocity of (a) $12.6 \mathrm{~m} / \mathrm{s}$ and (b) $6.4 \mathrm{~m} / \mathrm{s}$. Generally, the Nu value patterns display a similar trend with all H/D ratios. The highest number of Nusselt is the stagnation point of the 
pressure side surface recorded at $\mathrm{T} 2$ for both velocities. It can also be shown that the Nusselt number was decreased as the distance of the thermocouple from the centre point of the nozzle rose. The Nusselt number against H/D ratio at stagnation point was plotted in Figure 5 for further analysis.
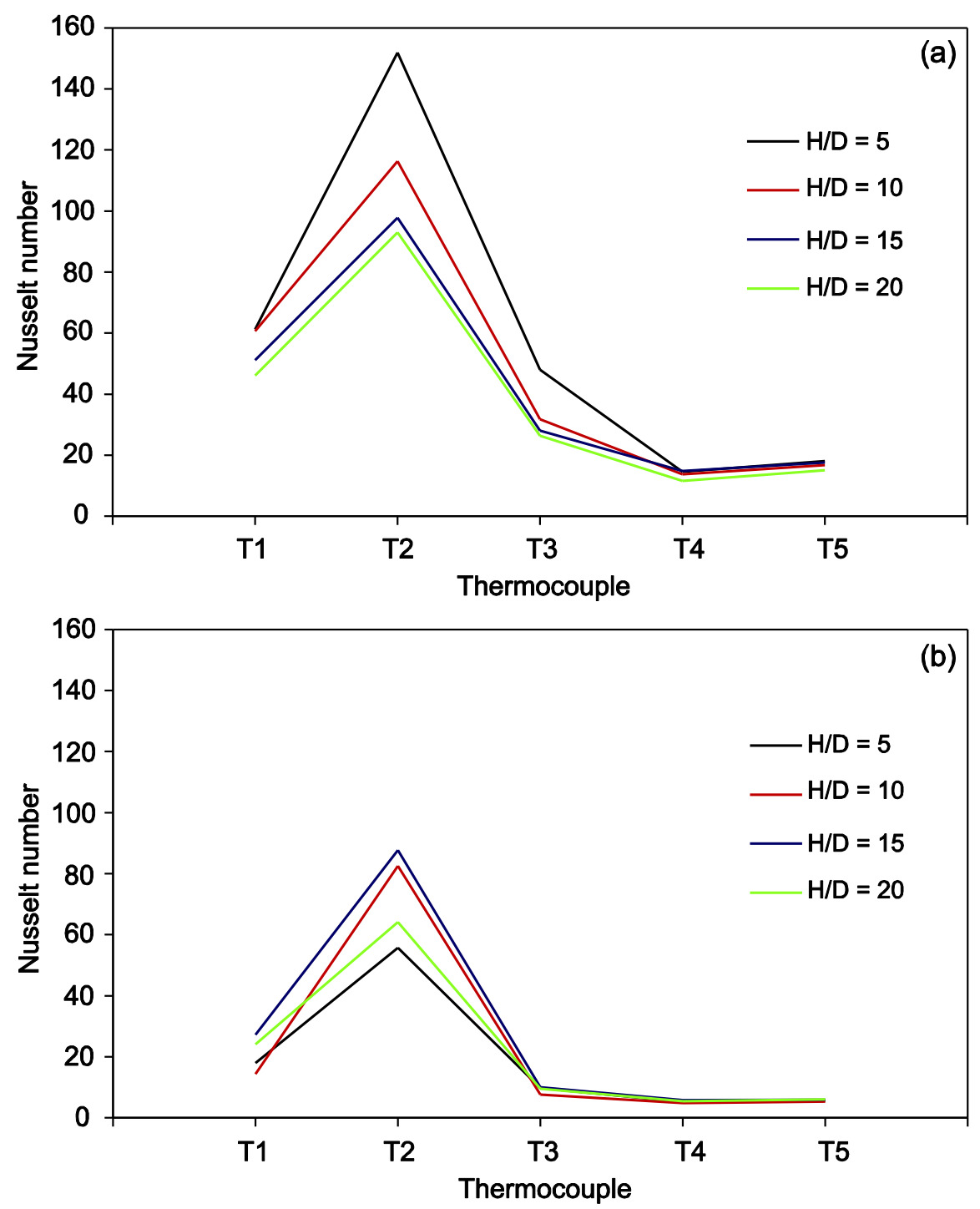

Fig. 4. Variation of Nusselt number of each thermocouple position with different $H / D$ at a velocity of (a) $12.6 \mathrm{~m} / \mathrm{s}$ and (b) $6.4 \mathrm{~m} / \mathrm{s}$

Figure 5 shows that under high velocity (V1) the Nusselt number rises with a decrease in the $H / D$ ratio. These results are compatible with previous studies by [19]. Nusselt dramatically decreased from $151.8418(H / D=5)$ to $97.6811(H / D=10)$ by 35.7 per cent and revealed a marginal decline in Nusselt by 4.9 per cent as the H/D ratio increased from 15 to 20. Figure 5 also indicates that under high velocity (V1) the highest amount of Nusselt number is 151.8418 , which is located at $H / D=5$. On the other side, under low velocity (V2), the amount of Nusselt rises by 57.6 per cent when the H/D ratio increases from 5 to 15 , but still declines by 26.9 per cent while $H / D=20$. Among the $H / D$ ratios, the maximum amount of Nusselt at low velocity (V2) is 87.6826 , which is considered to be at $H / D=15$. Based on Figure 5, the findings indicated that the $H / D$ ratio plays a major role in the performance of jet impingement cooling. Current studies have found that the optimum $H / D$ ratio at a velocity of $12.6 \mathrm{~m} / \mathrm{s}$ is $H / D=5$ and at a velocity of $6.4 \mathrm{~m} / \mathrm{s}$ is $H / D=15$. 
In the current analysis, the amount of Reynolds at a velocity of $12.6 \mathrm{~m} / \mathrm{s}$ and $6.4 \mathrm{~m} / \mathrm{s}$ is 3295.81 and 1674.06, respectively, suggesting that the experiment was performed under laminar flow conditions. It is interesting to note that there was no direct relationship between the Nusselt number and the H/D ratio at different velocity. In the case of high velocity, the Nusselt number decreased as the H/D ratio increased. Whereas for low velocity, the Nusselt number rose as the $H / D$ ratio increased and then decreased when the optimum H/D ratio was achieved.

Under high velocity, the Nusselt number rose as the H/D ratio declined due to lower H/D flow accelerations [21]. The performance of the heat transfer and the Nusselt number are associated with the cross-flow. The heat transfer to the surface raises the cross-flow [22]. As the H/D ratio raises, the cross-flow effect increases and hence decreases the effectiveness of the impingement cooling of the pressure side surface. In the other side, the Nusselt number rises with a rise in H/D from 5 to 15 at low velocity due to an increase in turbulence intensity. The rise in turbulence intensity is induced by interacting with ambient air and heat can be easily transmitted. However, the unexpected reduction in the Nusselt number at $H / D=20$ was attributed to the hot air beginning to travel upwards while the cold air from the nozzle persisted. When the nozzle distance is far from the plate, the compressed air coming out of the nozzle begins to disperse until it hit the plate, causing the hot air to travel upward, thereby decreasing the cooling power.

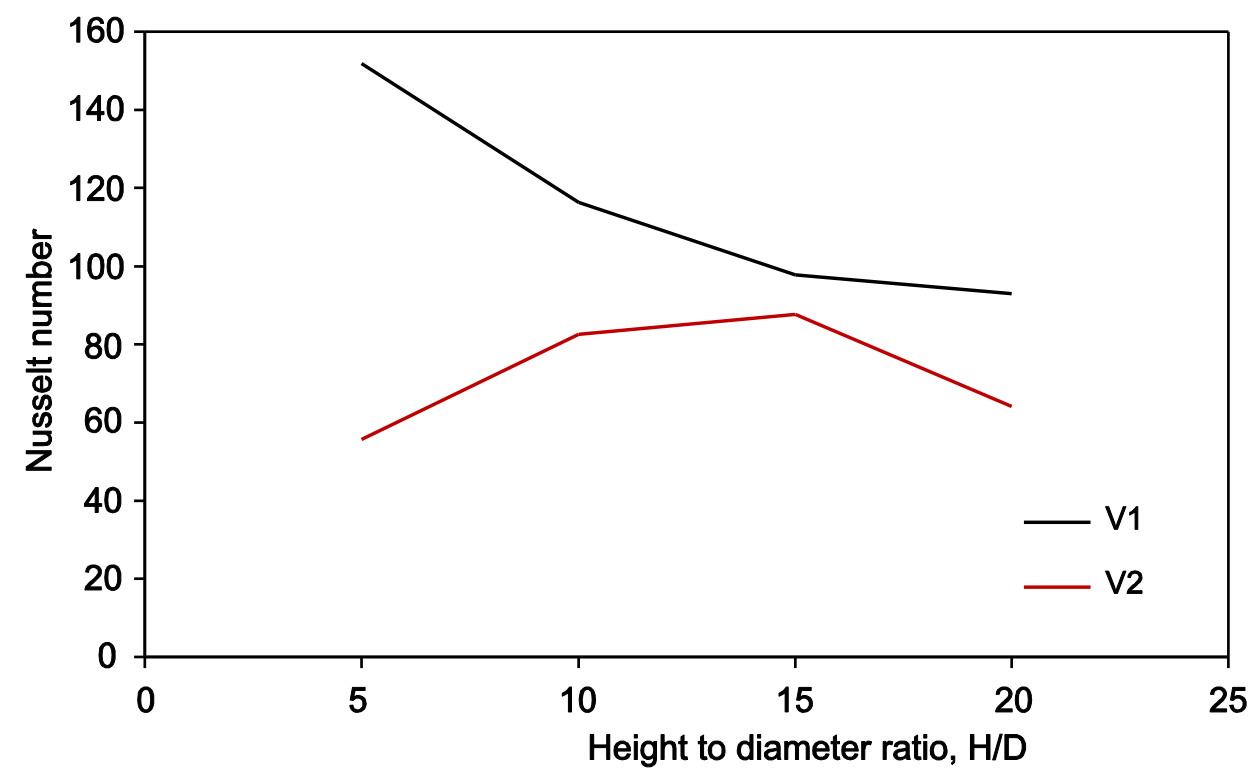

Fig. 5. Nusselt number versus $H / D$ ratio at stagnation point. $(V 1=12.6 \mathrm{~m} / \mathrm{s}$, $\mathrm{V} 2=6.4 \mathrm{~m} / \mathrm{s})$

\subsection{Effect of Velocity of Air}

The influence of the air velocity on the Nusselt number at optimum H/D is seen in Figure 6 . By contrast, the Nusselt number for V1 is greater than that for V2. Noted that the effectiveness of the jet impingement cooling system is determined based on the maximum Nusselt number [23]. This result has shown that $\mathrm{V} 1$ is far more effective than $\mathrm{V} 2$ in enhancing the jet impingement cooling system. Air velocity may affect the mass flow rate where the increasing velocity raises the mass flow rate. The mass flow rate is associated with the coefficient of heat transfer. As the coefficient of heat transfer rises, the amount of Nusselt increases. In particular, the direct role of the Nusselt number and the Reynolds number is also well assessed in the literature. Since the Reynolds number for velocity $12.6 \mathrm{~m} / \mathrm{s}$ is higher than those at $6.4 \mathrm{~m} / \mathrm{s}$, this explains why Nusselt number for V1 is 
larger than those of V2. In addition, based on the expression of turbulence intensity in the literature [22], the turbulence intensity was correlated with the Reynolds number. Thus, the strong turbulence intensity of V1 renders its Nusselt number higher than that of V2.

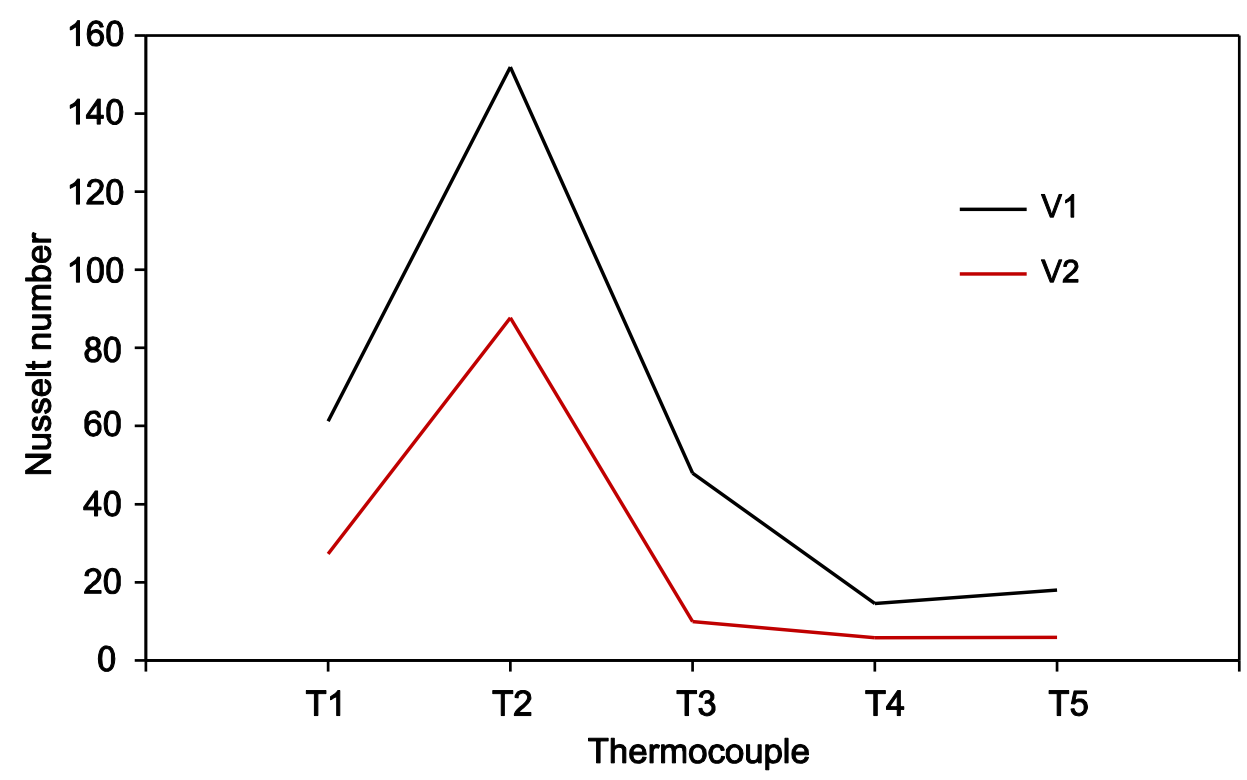

Fig. 6. Nusselt number versus thermocouple position at different velocities $(\mathrm{V} 1=12.6 \mathrm{~m} / \mathrm{s}, \mathrm{V} 2=6.4 \mathrm{~m} / \mathrm{s})$

\section{Conclusions}

Present research experimentally evaluated the effects of the height-to-diameter ratio (H/D) and the velocity of the air on the jet impingement cooling system of the pressure side model. The maximum number of Nusselt indicates the most effective cooling system for jet impingement. The findings of this study can be summarised in the following points

i. The Nusselt number at the stagnation point is greater than the other point on the pressure side of the model surface.

ii. No direct relationship between the Nusselt number and the height-to-diameter ratio (H/D) and the optimum $H / D$ at varying air velocity. The optimal $H / D$ for high air velocity $(12.6 \mathrm{~m} / \mathrm{s})$ is found to be at $H / D=5$, whereas at low air velocity $(6.4 \mathrm{~m} / \mathrm{s})$ it is found to be at $H / D=15$.

iii. The Nusselt number rises as the air velocity increases.

\section{Acknowledgement}

The authors would like to express their thanks to the Ministry of Higher Education of Malaysia for the FRGS Grant (FRGS/1/2018/TK03/UTM/02/14), Universiti Teknologi Malaysia (UTM)for the Research University Grant (21H50), TDR Grant (05G23) and FRGS Grant (5F074, 5F173).

\section{References}

[1] Nagaiah, Narasimha R., and Christopher D. Geiger. "Evolutionary numerical simulation approach for design optimization of gas turbine blade cooling channels." International Journal for Simulation and Multidisciplinary Design Optimization 5 (2014): A22. https://doi.org/10.1051/smdo/2014001

[2] Fan, Xiaojun, Liang Li, Jiasheng Zou, and Yuanyuan Zhou. "Cooling methods for gas turbine blade leading edge: Comparative study on impingement cooling, vortex cooling and double vortex cooling." International Communications in Heat and Mass Transfer $100 \quad$ (2019): $133-145$. https://doi.org/10.1016/i.icheatmasstransfer.2018.12.017 
[3] Nourin, Farah Nazifa, and Ryoichi S. Amano. "Review of Gas Turbine Internal Cooling Improvement Technology." Journal of Energy Resources Technology 143, no. 8 (2021): 080801. mprovement Technology." Journal of Energy Resources Technology 143, no. 8 (2021): 080801. https://doi.org/10.1115/1.4048865

[4] Zhao, Qing-Yang, Heeyoon Chung, Seok Min Choi, and Hyung Hee Cho. "Effect of guide wall on jet impingement cooling in blade leading edge channel." Journal of Mechanical Science and Technology 30, no. 2 (2016): 525-531. https://doi.org/10.1007/s12206-016-0105-x

[5] Salem, Abdel Rahman, Farah Nazifa Nourin, Mohammed Abousabae, and Ryoichi S. Amano. "Experimental and Numerical Study of Jet Impingement Cooling for Improved Gas Turbine Blade Internal Cooling With In-Line and Staggered Nozzle Arrays." Journal of Energy Resources Technology 143, no. $1 \quad$ (2021). https://doi.org/10.1115/1.4047600

[6] Razak, D. M., S. Syahrullail, N. Sapawe, Y. Azli, and N. Nuraliza. "A new approach using palm olein, palm kernel oil, and palm fatty acid distillate as alternative biolubricants: improving tribology in metal-on-metal contact." Tribology Transactions 58, no. 3 (2015): 511-517. https://doi.org/10.1080/10402004.2014.989348

[7] Jabal, Mohammed Hassan, Farid Nasir Ani, and S. Syahrullail. "The tribological characteristic of the blends of Rbd palm olein with mineral oil using four-ball tribotester." Jurnal Teknologi69, no. 6 (2014). https://doi.org/10.11113/it.v69.3232

[8] Hassan, Mohammed, Farid Nasir Ani, and S. Syahrullail. "Tribological performance of refined, bleached and deodorised palm olein blends bio-lubricants." Journal of Oil Palm Research 28, no. 4 (2016): 510-519. https://doi.org/10.21894/jopr.2016.2804.12

[9] Sapawe, N., Syahrullail Samion, P. Zulhanafi, C. S. Nor Azwadi, and M. F. Hanafi. "Effect of addition of tertiarybutyl hydroquinone into palm oil to reduce wear and friction using four-ball tribotester." Tribology Transactions 59, no. 5 (2016): 883-888. https://doi.org/10.1080/10402004.2015.1118584

[10] Syahrullail, S., M. A. M. Hariz, MK Abdul Hamid, and AR Abu Bakar. "Friction characteristic of mineral oil containing palm fatty acid distillate using four ball tribo-tester." Procedia Engineering 68 (2013): 166-171. https://doi.org/10.1016/i.proeng.2013.12.163

[11] Amiril, S. A. S., E. A. Rahim, Z. Embong, and S. Syahrullail. "Tribological investigations on the application of oilmiscible ionic liquids additives in modified Jatropha-based metalworking fluid." Tribology International 120 (2018): 520-534. https://doi.org/10.1016/i.triboint.2018.01.030

[12] Golshokouh, Iman, S. Syahrullail, Farid Nasir Ani, and H. H. Masjuki. "Investigation of Palm Fatty Acid Distillate Oil as an Alternative to Petrochemical Based Lubricant." Journal of Oil Palm Research 26, no. 1 (2014): 25-36.

[13] Kiu, Stephen Sie Kiong, Suzana Yusup, Chok Vui Soon, Taufiq Arpin, Syahrullail Samion, and Ruzaimah Nik Mohamad Kamil. "Tribological investigation of graphene as lubricant additive in vegetable oil." Journal of Physical Science 28 (2017): 257. https://doi.org/10.21315/ips2017.28.s1.17

[14] Ravanji, Abdolvahab, and Mehran Rajabi Zargarabadi. "Effects of pin-fin shape on cooling performance of a circular jet impinging on a flat surface." International Journal of Thermal Sciences 161 (2021): 106684. https://doi.org/10.1016/i.ijthermalsci.2020.106684

[15] Khalil, Mohammad Firdaus Mohammad, and Mohammad Nor Musa. "The Effectiveness of Jet Impingement Cooling System On Various Flat Plate Surface." Journal of Biolubricant Engineering and Science 1, no. 2 (2019).

[16] Yeranee, Kirttayoth, Makatar Wae-hayee, Yu Rao, and Chayut Nuntadusit. "Effects of air-induced duct diameter on flow and heat transfer characteristics of multiple impinging jets." Journal of Advanced Research in Fluid Mechanics and Thermal Sciences 51, no. 2 (2018): 247-258.

[17] Singh, Dushyant, B. Premachandran, and Sangeeta Kohli. "Effect of nozzle shape on jet impingement heat transfer from a circular cylinder." International Journal of Thermal Sciences 96 (2015): 45-69. https://doi.org/10.1016/j.ijthermalsci.2015.04.011

[18] Khaider, Abu Bakar. "Effect of nozzle angle on jet impingement cooling system." Faculty of Mechanical Engineering, Universiti Malaysia Pahang (2009).

[19] Liu, Zhao, and Zhenping Feng. "Numerical simulation on the effect of jet nozzle position on impingement cooling of gas turbine blade leading edge." International Journal of Heat and Mass Transfer 54, no. 23-24 (2011): 49494959. https://doi.org/10.1016/j.ijheatmasstransfer.2011.07.008

[20] Liu, Liangliang, Xiaocheng Zhu, Hao Liu, and Zhaohui Du. "Effect of tangential jet impingement on blade leading edge impingement heat transfer." Applied Thermal Engineering 130 (2018): 1380-1390. https://doi.org/10.1016/i.applthermaleng.2017.11.134

[21] Amano, Ryoichi S., and Bengt Sundén, eds. Impingement jet cooling in gas turbines. Vol. 25. WIT Press, 2014.

[22] Tepe, Ahmet Ümit, Yaşar Yetişken, Ünal Uysal, and Kamil Arslan. "Experimental and numerical investigation of jet impingement cooling using extended jet holes." International Journal of Heat and Mass Transfer 158 (2020): 119945. https://doi.org/10.1016/i.ijheatmasstransfer.2020.119945 
[23] Musa, Mohamad Nor, and Mohamed Izhar Mohamed Khalid. "Jet Impingement Cooling System on the Pressure Side of Turbine Blade." In Applied Mechanics and Materials, vol. 695, pp. 503-507. Trans Tech Publications Ltd, 2015. https://doi.org/10.4028/www.scientific.net/AMM.695.503 